\title{
Bresser-Pereira e a teoria do novo-desenvolvimentismo
}

André Roncaglia de Carvalho ${ }^{I}$

$\mathrm{O}$ LIVRO de Bresser-Pereira (2018) é uma das mais didáticas e bem acabadas exposições, até o momento, da teoria do novo-desenvolvimentismo, de cuja abordagem o autor é o expoente de maior destaque. O livro está organizado em três grandes partes, a saber: (1) um preâmbulo teórico acerca da relação entre Estado e mercado no capitalismo contemporâneo, seguido por uma demarcação da tradição desenvolvimentista que contextualiza o novo-desenvolvimentismo tanto no plano das políticas econômicas quanto no pensamento econômico (capítulos 1, 2 e 3); (2) uma leitura histórica do problema do desenvolvimento econômico no Brasil recente e os quatro principais desafios no caminho do pleno uso do potencial produtivo nacional (capítulos 4 e 5); e (3) o arranjo de política econômica centrado nos cinco preços macroeconômicos "corretos" e as reformas institucionais necessárias para o resgate de uma agenda de desenvolvimento econômico (capítulos 6 e 7).

Pelo seu formato, o livro é uma proposta de intervenção na realidade econômica do Brasil. Partindo da interpretação novo-desenvolvimentista da economia, o autor oferece as diretrizes gerais para um projeto de desenvolvimento nacional preocupado em mediar as interações entre Estado e mercado. O funcionamento eficiente do sistema produtivo disciplina o esforço dos indivíduos com vistas ao aumento da produtividade. Simultaneamente, a economia tem suas exigências moderadas pelo Estado e pelas institui- ções da sociedade civil, a qual direciona os impulsos da primeira para a distribuição mais equitativa da renda e da riqueza. Esse equilíbrio entre mercado e Estado está na raiz do que o autor entende por desenvolvimento econômico.

Nesse sentido, a primeira parte faz uma revisão da história moderna das sociedades ocidentais. O autor rejeita a polarização entre capitalismo e socialismo como quadro analítico para compreender o presente; prefere a dicotomia, aperfeiçoada por ele mesmo, entre os dois modelos de capitalismo, a saber: o liberalismo econômico e o desenvolvimentismo. O liberalismo relega o Estado à posição de mero garantidor da infraestrutura institucional de suporte ao setor privado. Já o desenvolvimentismo confere ao Estado um papel complementar ao mercado na coordenação da atividade econômica, tanto no plano macro quanto no microeconômico. Ao reescrever a história econômica como a alternância entre esses dois modelos de capitalismo (capítulos 3, 4 e 5), o autor insere uma abordagem dialética em sua narrativa, que lhe permite incorporar à sua análise as dimensões política e sociológica. Esse expediente reforça a convicção, há muito mantida pelo autor, de que a economia é uma ciência social que estuda os sistemas econômicos complexos em seus contextos social e histórico.

Com efeito, forças econômicas interagem dinamicamente com forças políticas (domésticas e estrangeiras) que disputam o comando do processo de 
mudança institucional. Os arranjos de políticas econômicas que emergem das coalizões entre grupos geram uma tensão entre a "eficiência" aos propósitos destes grupos e a "funcionalidade" para o desenvolvimento da coletividade. Nesse sentido, na narrativa de Bresser-Pereira, o liberalismo econômico é "eficiente" para os grupos no poder, mas se mostra disfuncional ao desenvolvimento de longo prazo da economia nacional. $\mathrm{O}$ desenvolvimentismo se apresenta como uma coalizão de industriais, trabalhadores e exportadores capazes de conter - e reverter - os excessos das frações da elite econômica que exaram aversão ao compartilhamento dos benefícios do crescimento com as classes trabalhadoras.

O Estado desempenha um papel importante nessa dinâmica, ao garantir não apenas os direitos propriedade e os contratos mas também as condições gerais do investimento privado (p.24). Além das cinco condições clássicas da acumulação de capital, relativas ao lado da oferta (educação, sistema monetário, suporte institucional aos mercados, infraestrutura e financiamento de longo prazo), adicionam-se duas outras. A sexta condição foi oferecida por Keynes e busca "neutralizar a tendência à insuficiência da demanda", via políticas fiscais e monetárias, de sorte a garantir às empresas um fluxo de renda sustentado que permita a expansão contínua da produção. Por fim, a sétima condição constitui a inovação teórica trazida por Bresser-Pereira e é a razão de ser do novo desenvolvimentismo: "neutralizar a tendência à sobreapreciação cíclica e crônica da taxa de câmbio" com vistas a promover o acesso à demanda externa e interna por parte das empresas que usam tecnologia no "estado da arte" (p.26).
Uma taxa de câmbio apreciada eleva o valor dos salários em moeda internacional, reduzindo a margem de lucro dos exportadores, inviabilizando a venda nos mercados internacionais. Note-se que isso implica um constrangimento determinante sobre a escala de produção dos empresários.

As coalizações de grupos levarão a diferentes aplicações das políticas de Estado sobre a economia. E aqui, ambos os programas estão expostos aos dois tipos de "irresponsabilidade no gastar" (p.29). Os liberais são mais propensos ao populismo cambial: altas taxas de juros apreciam a taxa de câmbio e transferem a demanda dos consumidores para o exterior, na forma de maiores importações. Os déficits em conta corrente atraem a poupança externa na forma de entrada de divisas estrangeiras que reforçam a apreciação cambial. Já os desenvolvimentistas sofrem mais da tentação do populismo fiscal, manifesto na inclinação ao gasto público indiscriminado e à geração de déficits fiscais elevados e crônicos. Esses desorganizam as contas públicas e geram pressão sobre a inflação, conduzindo a elevadas taxas de juros que deflagram o populismo cambial visto acima.

O capítulo 2 apresenta os principais elementos teóricos formativos do novo desenvolvimentismo. O autor lança mão de uma ferramenta retórica importante: a reinvenção da tradição (Arida 1996). Ainda que a intenção explícita do autor fosse a de mostrar as diferenças contextuais em que o desenvolvimentismo foi ampliando seu repertório temático, é difícil não notar uma busca implícita por uma reconstrução desnecessariamente linear (Whiggish) da história do pensamento desenvolvimentista como um 
acúmulo de progressos ao longo dos séculos.

É um recurso retórico comum na história do pensamento econômico "sentar-se sobre os ombros de gigantes", como forma de atribuir credibilidade e relevância a um esforço de reconstrução do pensamento. No caso presente, o risco dessa estratégia narrativa é tornar o conceito de desenvolvimentismo excessivamente elástico e, por vezes, com aplicação casuística e seletiva. Por exemplo, é questionável classificar como desenvolvimentistas economistas como Paul Krugman, Joseph Stiglitz e Dani Rodrik apenas por que esses economistas defendem um protagonismo maior do Estado no coordenação da economia (p.34). Nem todas as vertentes keynesianas se acomodam confortavelmente sob o guarda-chuva desenvolvimentista. Alternativamente, adotar o desenvolvimentismo implica necessariamente seguir a teoria de J. M. Keynes e, como já vimos, estendê-la para a realidade das economias abertas e, com a contribuição cepalina, das relações centro-periferia ou norte-sul.

É essa visão sistêmica que o novo desenvolvimentismo herda da economia do desenvolvimento do pós-Segunda Guerra. Sua principal proposição teórica é contraintuitiva e, por isso, carrega uma ousadia: países pobres não precisam de poupança externa para se desenvolver. A poupança baixa é uma das principais barreiras ao investimento sustentado de longo prazo. Logo, é intuitivo deduzir que um reforço vindo de fora seria útil. Todavia, o novo desenvolvimentismo alega que os capitais especulativos acabam sendo utilizados para financiar consumo e apreciar o câmbio, o que termina por reduzir a densidade industrial do país.
Por isso, o tipo de poupança externa é relevante: prefere-se o endividamento patrimonial, na forma de investimentos diretos no país (p.41). Por isso, não se opõe às empresas estrangeiras, contanto elas invistam no país. Esse investimento gerará, por sua vez, a poupança interna necessária para financiar a si próprio.

Nesse sentido, uma taxa de câmbio competitiva permite a obtenção de superávits na conta comercial, inibindo a tendência ao excesso de importações de bens de consumo e, por conseguinte, à entrada do capital financeiro especulativo. Todavia, para atingir esse resultado, a taxa de câmbio deve estar no nível "correto". Países abundantes em recursos naturais e humanos sofrem pressão para vender ao exterior produtos com baixo conteúdo tecnológico (agropecuária e indústria extrativa). Por serem altamente mecanizados, tais setores têm um custo relativamente baixo e, impulsionados pelos preços internacionais, acabam dominando a pauta de exportações. Atraem, portanto, forte volume de divisas estrangeiras, apreciando a taxa de câmbio e gerando desafios para setores intensivos em mão de obra e expostos à concorrência externa, como é o caso da indústria de transformação. Como o preço em dólares é fixado pelo mercado internacional, a apreciação cambial eleva o custo do trabalho, reduzindo a margem de lucro e a competitividade do produto exportado. Eis a doença holandesa a ser neutralizada. A saída aventada é curiosamente simples (p.48-53): basta taxar as empresas exportadoras de commodities na medida exata do diferencial entre as taxas de câmbio corrente (determinada pelo setor primário) e de equilíbrio industrial (determinada pela razão entre o custo efetivo do trabalho 
doméstico e internacional).

A taxa de câmbio tem ainda outros efeitos distributivos. Uma apreciação atua em favor dos salários de toda a economia e da renda de juros e de aluguéis (estimulando o consumo), enquanto reduz a competitividade e comprime as margens de lucro, em particular, das empresas industriais (tradables não commodities), desestimulando os investimentos em setores intensivos em tecnologia. No caso brasileiro, Bresser-Pereira (2007) há mais de dez anos vem apontando a perversa combinação de juros elevados e câmbio apreciado que mina a base para o arranque do desenvolvimento nacional.

Essa economia política explica as coalizões antidesenvolvimentistas: depreciar a taxa de câmbio confronta diretamente interesses das elites rentistas-financeiras, as quais, mundo afora, não têm qualquer compromisso com o desenvolvimento de longo prazo (Wolf 2018; Mazzucato; Jacobs 2016). Esses grupos conseguem uma aliança inusitada com os setores assalariados, os quais rejeitam a queda imediata do poder de compra dos salários que acompanha qualquer depreciação cambial, bloqueando qualquer apoio popular de maior escala ao projeto desenvolvimentista. Essa barreira tem também causas internas ao novo desenvolvimentismo, o qual se vê dividido internamente quanto à possibilidade efetiva de essa queda do salário real ser compensada indiretamente, protegendo os trabalhadores enquanto o salário real não volta a crescer.

Essa resistência de grupos de interesse inflige danos de longo prazo à sociedades em desenvolvimento. Similarmente à questão ambiental, a desindustrialização carrega consigo irreversibilidades prementes. Uma vez perdida qualquer etapa da cadeia produtiva, é altamente improvável que a depreciação cambial a traga de volta. Nesse sentido, a neutralização da doença holandesa não é panaceia: trata-se de uma medida preventiva contra o desmantelamento da densidade industrial e, portanto, em prol da competitividade internacional da indústria.

Essa incapacidade das elites brasileiras em construir um projeto nacional-desenvolvimentista se origina após a crise da dívida externa em 1982 e se acentua após a estabilização de 1994. O boom das commodities (2003-2007) mascara o problema da desindustrialização com superávits comerciais históricos que encobrem a rápida ascensão das importações. A irrupção da crise do subprime deixa novamente flagrante a crescente perda dos motores do dinamismo da economia brasileira e revela um enorme déficit comercial. A liquidez trilionária injetada pelos países desenvolvidos para proteger suas economias deprime as taxas de juros internacionais. Os capitais estrangeiros correm compulsivamente para financiar os crescentes gastos públicos domésticos, em busca da rentabilidade diferencial dos juros brasileiros. A taxa de câmbio vai-se apreciando e esmagando os lucros industriais. Os investimentos claudicam. O governo tenta reduzir custos das empresas via queda forçada da taxa de juros, represamento de preços administrados, desonerações fiscais indiscriminadas e injeção de crédito via bancos públicos a taxas subsidiadas. O abismo fiscal abre a sua garganta e, quando o malabarismo contábil se vê exposto, o governo se vê obrigado a cortar investimentos públicos. Os investimentos privados melhoram sua rentabilidade virtual, mas os lucros industriais mergulham e a confiança na economia 
vai soçobrando. A crise fiscal se instala e turbina a crise política e institucional que nos trouxe até o momento presente.

A agenda de políticas e reformas proposta pelo autor ataca os quatro grandes problemas (capítulo 5), a saber: a ausência de uma ideia de nação que impede uma agenda de longo prazo, o sistema eleitoral que estimula a corrupção na relação entre Executivo e Legislativo, a imensa desigualdade que impede o firmamento do pacto democrático e, por fim, a captura do patrimônio público via despesa com juros da dívida pública. A correção dos mecanismos distributivos disfuncionais ao desenvolvimento econômico (capítulo 6) requer colocar os cinco preços macroeconômicos no lugar. Os equilíbrios combinados do orçamento público e das contas externas permitem um binômio juro-câmbio que neutraliza a doença holandesa por meio de uma taxa de lucro satisfatória ao setor industrial. O crescimento moderado da taxa de salários facilita, por sua vez, o controle da taxa de inflação. O rigor com as contas públicas abre espaço para o Estado exercer, em complemento ao mercado, sua função coordenadora do sistema econômico.

Finalmente, do ponto de vista institucional, as reformas preveem a criação de um conselho de política cambial, a proibição da indexação formal dos contratos, uma política industrial permanente, um teto para a despesa corrente que não bloqueie o investimento público, uma reforma da previdência com idade mínima mais elevada mas que garanta direitos básicos, dentre outras.

Publicado em meados do ano, o livro defende um projeto de desenvolvimento que veio a ser rejeitado pelas urnas poucos meses depois. A eleição de uma pla- taforma com retórica ostensivamente antiestatal e antidemocrática é certamente anticlimática para quem esposa as ideias desenvolvimentistas do autor. Segundo Celso Furtado (1998, p.47), o desenvolvimento ocorre "quando a capacidade criativa do homem se volta para a descoberta de suas potencialidades, e ele se empenha em enriquecer o universo que o gerou". Se o diagnóstico que a obra de Bresser-Pereira nos oferece for confirmado, os próximos anos testemunharão mais uma vez o crepúsculo do desenvolvimento brasileiro. Continuaremos à sua espera no longo amanhecer da nossa consciência nacional.

\section{Referências}

ARIDA, P. A história do pensamento econômico como teoria e retórica. In: REGO, J. M. Retórica na Economia. São Paulo: Editora 34, 1996.

BRESSER-PEREIRA, L. C. Macroeconomia da estagnação: critica da ortodoxia convencional no brasil pos-1994. São Paulo: Editora 34, 2007.

\section{Em busca do desenvolvimento per-}

dido: um projeto novo-desenvolvimentista para o Brasil. São Paulo: Editora da FGV, 2018.

FURTADO, C. O capitalismo global. 7.ed. São Paulo: Paz e Terra, 1998.

MAZZUCATO, M.; JACOBS, M. Rethinking Capitalism: Economics and Policy for Sustainable and Inclusive Growth. Wiley \& Political Quarterly, 2016.

WOLF, M. Why so little has changed since the financial crash. Financial Times, 4 set. 2018 .

André Roncaglia de Carvalho é doutor em economia do desenvolvimento pela 
Faculdade de Economia, Administração, Contabilidade e Atuária e professor adjunto de ciências econômicas da Escola Paulista de Política, Economia e Negócios da Universidade Federal de São Paulo (EPPEN-Unifesp), Osasco.

@-andre.carvalho@unifesp.br /

https://orcid.org/0000-0003-4873-3433

Recebido em 12.11.2018 e aceito 15.12.2018.

I Escola Paulista de Política, Economia e Negócios, Universidade Federal de São Paulo, Osasco, São Paulo, Brasil. 